\title{
What do People with Diabetes Distress want from their Diabetes Care Providers: Are there Gender Differences?
}

\author{
Gemma C Macdonald ${ }^{1}$ and Lesley V Campbell ${ }^{1,2,3 *}$ \\ ${ }^{1}$ Diabetes Centre, St Vincent's Hospital, Australia \\ ${ }^{2}$ St Vincent's Clinical School, UNSW Sydney, Australia \\ ${ }^{3}$ Diabetes and Metabolism Division, Garvan Institute of Medical Research, Australia
}

Submission: November 27, 2018; Published: January 08, 2019

*Corresponding author: Lesley Campbell, Diabetes Centre, St Vincent's Hospital, Level 4, Garvan Institute of Medical Research, 384 Victoria Street, Darlinghurst NSW 2010, Australia

\begin{abstract}
Purpose: Analyze a survey of feelings and perspective on past diabetes education and care and compare with literature, highlighting continuing gaps in current care, especially noting gender differences. Results could provide insights to help improve diabetes care and reduce mental health burden.

Methods: Thirty-two people with diabetes (63\% female, $75 \%$ with type 2 diabetes, $65 \pm 8$ years old) were anonymously surveyed, providing quantitative demographic data regarding participant characteristics and emotional distress and qualitative data on participant perceptions and experiences. Responses and results were reviewed in current clinical context.

Results: Over 50\% of participants experienced some distress: $25 \%$ had negative perceptions of their current diabetes care. Significantly more women expressed feelings of being overwhelmed by their diabetes. Information about complications motivated them most strongly. This effect was greater in men, with women more likely to experience associated diabetes distress. Qualitative responses provided an insight into the daily challenges faced by people with diabetes, especially women. Themes of blame, guilt and fear were common, with suggestions for improved care in a manner similar to recommendations in psychosocial literature.

Conclusion: People with diabetes report experiencing negative attitudes from their diabetes care providers, contributing to diabetes distress, despite extensive literature recommending the opposite care practice. From the patient's viewpoint, literature recommendations regarding supportive "person-centered" diabetes care and education need to be practiced at diagnosis, as well as during treatment. Perhaps further understanding of gender-specific diabetes educational approaches could also improve mental health outcomes, especially altering focus on complications as motivation in women.
\end{abstract}

Keywords: Diabetes distress; Diabetes education; Diabetes care; Survey; Gender difference; Educational approach; Person-centered care; Diabetes complications

\section{Introduction}

Diabetes distress is defined as the emotional response to living with diabetes [1]. Interest in diabetes distress is increasing as it is twice as common as major depression [2], estimated to affect one in four with type 1 diabetes and one in five with type 2 diabetes [3]. Women with diabetes have poorer clinical and "personcentered" diabetes outcomes than men [4]. Understanding why these differences exist through qualitative study may help reduce diabetes distress, especially in women.

Diabetes mellitus is a complex metabolic condition with an inescapable daily self-management burden involving daily disease reminders and life-style intrusions, often producing strain in relationships with family, friends, and work colleagues
[5]. Diabetes-related social stigma is common in both type 1 and type 2 diabetes [6,7]. Well-intentioned professionals, family and friends exacerbate anxiety and guilt by highlighting inadequate glycemic control and warning of increased complication risk. No other condition carries similar blame and guilt related to the basic disease process as occurs with hyperglycemia.

Anderson and Funnell highlight that most of the literature focuses on the "problem" of patient behavior [8]. The use of threats or fear-based persuasion in diabetes care increases mental health burden [9]. These fears include hyperglycemia (complications), hypoglycemia, and death. Future complications are often simply seen as patient failure rather than, at least partly, a result of 
heritable factors (both protective and/or predisposing) [10]. Due to the relentless demands of this condition, depressive symptoms and emotional distress are currently accepted as a "normal" part of the diabetes experience $[11,12]$.

Mental illness burden is often ignored in diabetes populations, focusing on physical issues of diabetes [13]. However, studies suggest treatment of mental health disorders in diabetes improves outcomes $[14,15]$. Undesirable sequelae of untreated mental health disorders include hyper- and hypoglycemia, worse health and quality of life, as well as diabetic complications and death and the psychological burden can become a barrier to better diabetes management [16]. Gonzalez and colleagues' express concerns with over-pathologizing mental health disorders in diabetes, suggesting emotional symptoms in the context of diabetes are not understood [11].

Recently Sturt and colleagues published an extensive review and meta-analysis of randomized controlled trials of intervention studies for diabetes distress and found diabetes self-management education interventions alone didn't significantly alleviate diabetes distress [14]. Also, the American Diabetes Association published a position statement on psychosocial care for people with diabetes and recommended "diabetes education", but without conclusive evidence to support this recommendation [17].

This study investigated:

a) Evidence of distress in people with diabetes

b) Their views on past diabetes education and care, examining for gender differences.

c) How survey outcomes fit with current care recommendations were assessed.

As diabetes education is recommended as treatment for diabetes distress, the survey was done to find out what aspects of diabetes education alleviated diabetes distress and what may further exacerbate this complex condition.

\section{Research Design and Methodology}

\section{Setting and participants}

Participants were members of "Diabetes \& ACT living with Diabetes" and were recruited at the "Live Your Life Member Forum" presented at Parliament House, Sydney, Australia, in November 2016. This forum registered 185 adults and was presented on World Diabetes Day for people living with, or at risk of, diabetes and their careers, family and friends. The forum focused on practical advice from health professionals to enhance health care and improve quality of life. Fifty-eight people attending the "Diabetes Distress" workshop presented by Professor Lesley Campbell were invited to answer an anonymous survey at the end of the presentation. Most were aged over 50 years: no one was excluded from the survey.

\section{Procedures}

All attendees at the "Diabetes Distress" workshop who completed the survey were asked about diabetes distress and their perceptions of past diabetes care. Survey responses were analyzed by both authors and basic statistics analyzed by G Macdonald with assistance from A Jenkins.

\section{Measures}

The survey was developed at St Vincent's Hospital, Sydney by the authors and included general information (age, gender, diabetes type), questions based on Diabetes Distress Scale - 2 screening instruments [18], questions surrounding diabetes education, such as motivation by complications, helpful attitudes for weight management, and what could be done differently in diabetes education. A copy of the survey is attached in the supplementary section.

\section{Statistical analysis}

General demographics are presented as sample size and percentages, except age, which is presented as mean and standard deviation. Responses to qualitative questions are presented as sample size and percentages. Effects of gender on responses were assessed using chi-squared test in R [19]. Relationships between diabetes distress and motivation were also analyzed, especially related to gender difference.

\section{Results}

\section{General response analysis}

Thirty-two people completed the surveys. Their mean age was $65 \pm 8$ years, predominantly women (63\%); $75 \%$ had type 2 diabetes (Table 1).

Table 1: Basic demographics of participants $(n=32),{ }^{*}$ Other represents: one participant without diabetes and one with pre-diabetes.

\begin{tabular}{|c|c|c|}
\hline \multirow{2}{*}{ Sex } & Women & Number of Participants (\%) \\
\cline { 2 - 3 } & Men & $20(63 \%)$ \\
\hline \multirow{3}{*}{ Diabetes Type } & Type 1 & $12(37 \%)$ \\
\cline { 2 - 3 } & Type 2 & $6(19 \%)$ \\
\cline { 2 - 3 } & Other* & $24(75 \%)$ \\
\hline & & $2(6 \%)$ \\
\hline
\end{tabular}




\section{Current Research in Diabetes \& Obesity Journal}

\begin{tabular}{|l|c|c|}
\hline \multirow{2}{*}{ Age (yr) } & Range & $43-76$ \\
\cline { 2 - 3 } & Mean (Standard deviation) & $65( \pm 8)$ \\
\hline
\end{tabular}

\section{Living with diabetes}

Over half of the participants were overwhelmed by the demands of living with diabetes (Table 2) and felt that they often failed with their diabetes regimen (Table 2), suggesting over half responded positively for some level of diabetes distress. This response was greater in women than men (Table 2) and is stronger with the question about feeling overwhelmed, where a significant gender difference was found ( $p=0.035)$. In type 2 diabetes twothirds of women $(66.7 \%)$ felt overwhelmed compared to $11.1 \%$ of men, also a significant gender effect $(p=0.026)$.

Table 2: Quantitative results from survey, including questions on "feeling overwhelmed by the demands of living with diabetes", "feelings of often failing with diabetes regimen", and "motivation by hearing about the complications of diabetes". * Distress defined by a yes response to at least one of these questions: "feeling overwhelmed by the demands of living with diabetes" and "feelings of often failing with diabetes regimen".

\begin{tabular}{|c|c|c|c|c|c|}
\hline & & All n=32 & Women n=20 & Men n=12 & p (Gender Effect) \\
\hline \multirow{2}{*}{ Feeling overwhelmed } & Yes & $17(53 \%)$ & $14(70 \%)$ & $3(25 \%)$ & 0.035 \\
\cline { 2 - 6 } & No & $15(47 \%)$ & $6(30 \%)$ & $9(75 \%)$ & $5(42 \%)$ \\
\hline \multirow{2}{*}{ Feeling often failing } & Yes & $18(56 \%)$ & $13(65 \%)$ & $7(58 \%)$ & 0.36 \\
\cline { 2 - 6 } & No & $14(44 \%)$ & $7(35 \%)$ & $11(92 \%)$ & 0.32 \\
\hline \multirow{2}{*}{ Motivated by complications } & Yes & $25(78 \%)$ & $14(70 \%)$ & $1(8 \%)$ & \\
\cline { 2 - 6 } & No & $7(22 \%)$ & $6(30 \%)$ & Men n=11 & \\
\hline & & & Women n=13 & $5(45 \%)$ & 0.039 \\
\hline
\end{tabular}

In response to the first question, "Do you feel overwhelmed by the demands of living with diabetes?", a few themes emerged. Participants not overwhelmed still experienced negative effects, "But it does take over your life" and "[I] sometimes get down". Diabetes self-management was adversely affected by life events such as a death in the family, illness, and travel. The theme of being tough and getting on with it was common: "I am a survivor" and "understand the daily demand and requirement".

In response to the second question, "Do you feel that you are often failing with your diabetes regimen?", the comments revealed participants believe they have a good understanding of diabetes care but find real life situations hard.

\section{Diabetes education}

Most participants were motivated by hearing about the complications of diabetes; this effect being greater in men than women (Table 2). Of those motivated by hearing about complications, women were significantly $(\mathrm{p}=0.039)$ more distressed than men (Table 2). This awareness of complications combined with negative emotions in women can be seen in the comments, "Certainly brings it home! Does scare me -", "This really stress [es me] + I feel very low and depressed" and "It makes me feel more overwhelmed".

In response to the question about weight problems and health carers attitudes a quarter (25\%) expressed negative opinions about current care, "Don't feel they are all that helpful" and "Any health care (apart from endocrinologist) has been extremely "lame" including GP". The participants suggested helpful attitudes included encouragement, interest and cooperation. Just under half (44\%, 7 out of 16 comments) said that they appreciated factual information related to diet and exercise.

Many themes were raised in response to the question, "What do you think should be done differently in current diabetes education?" They included behaviors recommended in the literature, such as acknowledging peoples' efforts, reducing blame and guilt, providing patient-specific information [20]. There were both positive $(15 \%, 3 / 20)$ and negative $(10 \%, 2 / 20)$ feelings about current diabetes care. One participant, a female with type 2 diabetes commented “I haven't been [involved in] any of the diabetes education program[s]" and she showed no diabetes distress.

Many participants provided comments conveying the burden of guilt about diet and exercise behaviors, e.g. "Choosing what food + controlling my will power", "WHY ME? - Guilt, burden - difficult to manage", "Sometimes I know I'll eat the wrong thing", "Always feeling guilty not moving \& diet." and "I will try to move more".

\section{Conclusion}

This anonymous study surveyed diabetes distress and perceptions of diabetes care in 32 people. Overall diabetes distress was high, especially in women. The literature suggests gender differences, with women suffering more[4]. Rossi and colleagues discuss gender-specific approaches in response to the diabetes mental health burden. This raises the question as to whether traditional diabetes management caters better to men with the burden of diabetes management weighing more heavily 


\section{Current Research in Diabetes \& Obesity Journal}

on women. The survey results support this view with further qualitative evidence.

Diabetes diagnosis increases the risk of mental health burden [21] and this burden increases over time [22]. However, the study findings align with previous literature [2,3] providing supportive evidence that traditional diabetes education, with fear-based persuasion [9] can contribute to the high distress. As reported, one participant (woman, 70 years) who appeared to not be distressed, commented "I haven't been [involved in] any of the diabetes education program[s]". Perhaps not being exposed to diabetes education protected this participant?

Diabetes education depends on learning risk factors and complications associated with diabetes, making appropriate food choices and being physically active, performing glucose monitoring and understanding use of medication. "Compliant" patients accept and strive for the targets for health and diabetes. Many issues such as excess weight or effects of hyperglycemia produce fear, guilt, and shame. Current diabetes distress treatment highlights a need for "more diabetes education", however whether such education should be better tailored is not discussed [17].

One research group targeting diabetes distress repeatedly endorses diabetes self-management education as a diabetes distress treatment $[12,23]$. However, they state the evidence is not clear about self-management or diabetes education reducing diabetes distress and recommend targeting distress directly [1]. It seems that acknowledgment of diabetes stressors and normalizing them as part of the diabetes experience is an important part of diabetes education and perhaps is responsible for the overall success of their main study (REDEEM), especially for those with low levels of distress [12]. Fisher and colleagues suggest in cases of higher distress a problem-solving intervention that targets distress directly may be beneficial, by people identifying and defining their distress [1]. With more severe distress they suggest stronger interventions such as psychological and drug therapies [1]; however, Sturt and colleagues reported no scientific evidence to support this [14].

A handbook on diabetes and emotional health developed by Diabetes Australia suggests offering education programs for diabetes distress [3]. One-off diabetes management education programs may provide short-term benefit, however Funnell and Anderson highlight that these programs rarely provide longterm benefit in sustained behavioral change [24]. Anderson \& Funnell [8] discuss the importance of recognizing and meeting the patient's needs for long-term support. Developing long-term relationships requires trust, with patients able to express lifestyle choices and feelings in a non-judgmental environment and health professionals not feeling directly responsible for the patient's actions and outcomes [25]. Schwartz and colleagues discuss the patient-provider relationship and diabetes medical adherence, suggesting trust is developed through better care provider communication, empathy, non-judgmental and genuine concern for the patient [26]. They also discuss difference in perceptions between patient and care providers, with patients focusing on personal, social, and practical challenges and care providers on medical problem solving. Altogether, this research suggests that the relationship between patient and care provider is more important than traditional diabetes education. This is supported by Sturt et al. [14] results that generalist care providers rather than diabetes or psychology professionals were associated with reduced diabetes distress, and a higher frequency of sessions over longer duration reduced diabetes distress. The ease of access and continuity of care of generalist care providers as well as longer time to develop relationships support the centrality of patientprovider relationship.

Attempts at motivation by discussing complications can induce fear in women, e.g. "Certainly brings it home! Does scare me -" and "This really stress + I feel very low and depressed". Men appear more practical, e.g. "[it keeps] me on alert", "Need to be aware of my condition". This gender difference may relate to differences in gender coping strategies or be due to stereotypes, with men feeling greater pressure to appear "tough". Perhaps diabetes education in the area of complications needs to be modified, especially with women.

Helpful provider attitudes, for example encouragement, acknowledging effort, providing patient-specific information, using non-judgmental language, etc., mirror "person-centered care" principles and are repeatedly recommended in diabetes care literature $[17,27]$. However, the study findings support previous evidence of a lack of "person-centered care", reported in a 2011 survey where almost half the responders were never asked what was important to them in their diabetes care and only half received the information that they felt they needed [28].

Change in care providers' attitudes and behavior still appears necessary to alleviate patient's fear, guilt and self-blame. One study reported almost a third of participants were reluctant to discuss self-care with their primary healthcare professional, with participants misrepresenting or withholding information "not wanting to disappoint their diabetes doctor or not wanting to feel judged by their doctor" or having feelings of "shame, guilt and embarrassment" [29]. A web-survey by de Wit \& Snoek reported half did not talk with health professionals about their feelings surrounding their depressive symptoms [30]. Importantly, people with diabetes are actually relieved when health professionals initiate discussions about distress [11]. Addressing and talking about feelings can be therapeutic and may inspire behavior changes [11].

The complexity of living with diabetes was highlighted by the survey results, especially as participants who were not overwhelmed still expressed difficulties. One participant called himself a "survivor" suggesting he has coped where others did not. Given the life-long burden of diabetes, it is understandable that keeping diabetes management a priority is difficult, especially during stress. The survey reinforces Greenfield and colleagues' findings that, instead of not understanding diabetes management, 


\section{Current Research in Diabetes \& Obesity Journal}

people with diabetes understand only too well the struggle to manage this condition within their life and social situation [31]. This highlights the enormity of living with diabetes against the sometimes-impossible expectations of care providers.

Limitations of the current study include small sample size, predominantly females with type 2 diabetes. Also, participants were self-selected, choosing to attend the diabetes distress workshop. However; very small studies in this area are commonly referenced due to the lack of larger studies.

In summary, when asked their perspectives on their past diabetes education and care, over half the people with diabetes surveyed experienced diabetes distress, especially women, with a quarter expressing negative perceptions of their diabetes care. Participants also provided further insights into their daily challenges with diabetes, suggesting an urgent need for change in diabetes care providers' attitudes. Aspects of diabetes education which alleviate diabetes distress using "person-centered care" principles are described in the literature. Fear, guilt and shame, especially related to use of complication/risk of diabetes as motivation in women, appear instead to exacerbate diabetes distress. People with diabetes today still experience negative attitudes within diabetes education from diagnosis onwards which may contribute to their high levels of emotional distress. The lesson for diabetes educators (and diabetes careers) from this survey reinforces the concept that fear-inducing warnings about diabetes complications intended to induce "compliance" may rather contribute to diabetes distress, particularly in women.

\section{Acknowledgement}

We thank the late Mr W. R. Galvin O.A.M. for his financial support, which generously supported the research undertaken by Gemma Macdonald in preparation of this publication. We thank Dr Arthur Jenkins (Honorary Principal Fellow at the University of Wollongong, Australia) for his assistance with our statistical analysis.

\section{Declaration of Conflicting Interests}

The authors, Ms Gemma Macdonald and Professor Lesley Campbell, declare that there is no conflict of interest.

\section{References}

1. Fisher L, Gonzalez JS, Polonsky WH (2014) The confusing tale of depression and distress in patients with diabetes: a call for greater clarity and precision. Diabet Med 31(7): 764-772.

2. Fisher L, Mullan JT, Arean P, Glasgow RE, Hessler D, et al. (2010) Diabetes Distress but Not Clinical Depression or Depressive Symptoms is Associated with Glycemic Control in Both Cross-Sectional and Longitudinal Analyses. Diabetes Care 33(1): 23-28.

3. Hendrieckx C, Halliday JA, Beeney LJ, Speight J (2016) Diabetes and emotional health: a handbook for health professionals supporting adults with type 1 or type 2 diabetes. Canberra: National Diabetes Services Scheme, Australia.

4. Rossi MC, Lucisano G, Pintaudi B, Bulotta A, Gentile S, et al. (2017) The complex interplay between clinical and person-centered diabetes outcomes in the two genders. Health Qual Life Outcomes 15(1): 41.
5. Tanenbaum ML, Gonzalez JS (2012) The influence of diabetes on a clinician-rated assessment of depression in adults with type 1 diabetes. Diabetes Educ 38(5): 695-704.

6. Browne JL, Ventura A, Mosely K, Speight J (2014) 'I'm not a druggie, I'm just a diabetic': a qualitative study of stigma from the perspective of adults with type 1 diabetes. BMJ Open 4(7): e005625.

7. Browne JL, Ventura A, Mosely K, Speight J (2013) s call it the blame and shame disease': a qualitative study about perceptions of social stigma surrounding type 2 diabetes. BMJ Open. 3(11): e003384.

8. Anderson RM, Funnell MM (2010) Patient empowerment: myths and misconceptions. Patient Educ Couns 79(3): 277-282.

9. Lawson VL, Bundy C, Harvey JN (2008) The development of personal models of diabetes in the first 2 years after diagnosis: a prospective longitudinal study. Diabet Med 25(4): 482-490.

10. Sambo F, Malovini A, Sandholm N, Stavarachi M, Forsblom C, et al. (2014) Novel genetic susceptibility loci for diabetic end-stage renal disease identified through robust naive Bayes classification. Diabetologia 57(8): 1611-1622.

11. Gonzalez JS, Fisher L, Polonsky WH (2011) Depression in diabetes: have we been missing something important? Diabetes Care 34(1): 236-239.

12. Fisher L, Hessler D, Glasgow RE, Arean PA, Masharani U, et al. (2013) REDEEM: a pragmatic trial to reduce diabetes distress. Diabetes Care 36(9): 2551-2558.

13. Macdonald G, Campbell L (2016) Mental illness: the forgotten burden on diabetes populations? The Lancet 388(10044): 561.

14. Sturt J, Dennick K, Hessler D, Hunter BM, Oliver J, et al. (2015) Effective interventions for reducing diabetes distress: systematic review and meta-analysis. International Diabetes Nursing 12: 40-55.

15. Penckofer S, Doyle T, Byrn M, Lustman PJ (2014) State of the science: depression and type 2 diabetes. West J Nurs Res 36(9): 1158-1182.

16. Snoek FJ, Bremmer MA, Hermanns N (2015) Constructs of depression and distress in diabetes: time for an appraisal. Lancet Diabetes Endocrinol 3(6): 450-460.

17. Young-Hyman D, de Groot M, Hill-Briggs F, Gonzalez JS, Hood K, et al. (2016) Psychosocial care for people with diabetes: a position statement of the American Diabetes Association. Diabetes Care 39(12): 2126-2140.

18. Fisher L, Glasgow RE, Mullan JT, Skaff MM, Polonsky WH. (2008) Development of a Brief Diabetes Distress Screening Instrument. Ann Fam Med 6(3): 246-252.

19. R Core Team (2016) R: A language and environment for statistical computing. R Foundation for Statistical Computing, Vienna, Austria.

20.Skinner T (2016) Diabetes distress and depression: can we prevent them? 2016 Australian Diabetes Society \& Australian Diabetes Educators Association Annual Scientific Meeting, Australia

21. Nouwen A, Nefs G, Caramlau I, Connock M, Winkley K, et al. (2011) Prevalence of depression in individuals with impaired glucose metabolism or undiagnosed diabetes: a systematic review and metaanalysis of the European Depression in Diabetes (EDID) Research Consortium. Diabetes Care 34(3): 752-762.

22. Thoolen BJ, de Ridder DT, Bensing JM, Gorter KJ, Rutten GE (2006) Psychological outcomes of patients with screen-detected type 2 diabetes: the influence of time since diagnosis and treatment intensity. Diabetes Care 29(10): 2257-2262.

23. Fisher L, Hessler D, Masharani U, Strycker L (2014) Impact of baseline patient characteristics on interventions to reduce diabetes distress: the role of personal conscientiousness and diabetes self-efficacy. Diabet Med 31(6): 739-746. 


\section{Current Research in Diabetes \& Obesity Journal}

24. Funnell MM, Anderson RM (2004) Empowerment and SelfManagement of Diabetes. Clinical Diabetes 22(3): 123-127.

25. Fiore V, Marci M, Poggi A, Giagulli VA, Licchelli B, et al. (2015) The association between diabetes and depression: a very disabling condition. Endocrine 48(1): 14-24.

26. Schwartz DD, Stewart SD, Aikens JE, Bussell JK, Osborn CY, et al. (2017) Seeing the Person, Not the Illness: Promoting Diabetes Medication Adherence Through Patient-Centered Collaboration. Clin Diabetes 35(1): 35-42.

27. Dickinson JK, Guzman SJ, Maryniuk MD, O’Brian CA, Kadohiro JK, et al. (2017) The Use of Language in Diabetes Care and Education. Diabetes Care 40(12): 1790-1799.

28. Speight J, Browne JL, Holmes-Truscott E, Hendrieckx C, Pouwer F (2011) On behalf of the Diabetes MILES - Australia reference group

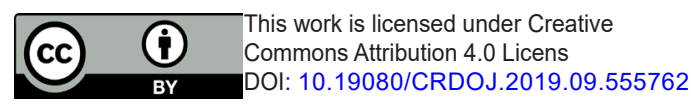

(2011) Diabetes MILES - Australia 2011 Survey Report. Diabetes Australia - Vic, Melbourne.

29. Beverly EA, Ganda OP, Ritholz MD, Lee Y, Brooks KM, et al. (2012) Look who's (not) talking: diabetic patients' willingness to discuss self-care with physicians. Diabetes Care 35(7): 1466-1472.

30. de Wit M, Snoek FJ (2011) Depressive symptoms and unmet psychological needs of Dutch youth with type 1 diabetes: results of a web-survey. Pediatr Diabetes. 12(3 Pt 1): 172-176.

31. Greenfield C, Gilles M, Porter C, Shaw P, Willis K (2011) It's not just about the HbA1c, Doc! Understanding the psychosocial is also important in managing diabetes? Aust J Rural Health 19(1): 15-19.

Your next submission with Juniper Publishers
will reach you the below assets
- Quality Editorial service
- Swift Peer Review
- Reprints availability
- E-prints Service
- Manuscript Podcast for convenient understanding
- Global attainment for your research
- Manuscript accessibility in different formats
( Pdf, E-pub, Full Text, Audio)
- Unceasing customer service
Track the below URL for one-step submission
https://juniperpublishers.com/online-submission.php

